\title{
Identification of 74 cytochrome P450 genes and co-localized cytochrome P450 genes of the CYP2K, CYP5A, and CYP46A subfamilies in the mangrove killifish Kryptolebias marmoratus
}

\author{
Bo-Young Lee ${ }^{\dagger}$, Duck-Hyun Kim, Hui-Su Kim, Bo-Mi Kim, Jeonghoon Han and Jae-Seong Lee ${ }^{*}$ (1)
}

\begin{abstract}
Background: The mangrove killifish Kryptolebias marmoratus is the only vertebrate that reproduces by self-fertilizing and is an important model species in genetics and marine ecotoxicology. Using whole-genome and transcriptome sequences, we identified all members of the cytochrome P450 (CYP) family in this model teleost and compared them with those of other teleosts.

Results: A total of 74 cytochrome P450 genes and one pseudogene were identified in K. marmoratus. Phylogenetic analysis indicated that the CYP genes in clan 2 were most expanded, while synteny analysis with other species showed orthologous relationships of CYP subfamilies among teleosts. In addition to the CYP2K expansions, five tandem duplicated gene copies of CYP5A were observed. These features were unique to K. marmoratus.

Conclusions: These results shed a light on CYP gene evolution, particularly the co-localized CYP2K, CYP5A, and CYP46A subfamilies in fish. Future studies of CYP expression could identify specific endogenous and exogenous environmental factors that triggered the evolution of tandem CYP duplication in K. marmoratus.
\end{abstract}

Keywords: Rivulus, Killifish, Model animal, Gene family expansion, Drug metabolism, Tandem duplication

\section{Background}

Cytochrome P450 (CYP) enzymes are heme-containing proteins that play critical roles in the metabolism of endogenous substrates (e.g., hormones and vitamins) and in the detoxification of xenobiotics (e.g., drugs and environmental pollutants) [1-5]. Together, the CYPs constitute one of the most diverse gene families. Different species, even closely related ones, can have different numbers of CYP genes [6, 7]. The CYP genes are hierarchically classified at three distinct levels into subfamilies, families, and clans based on their amino acid sequence similarity, phylogenetic relationships, and syntenic relationships [6-8]. Molecular phylogenetic studies have identified

\footnotetext{
* Correspondence: jslee2@skku.edu

${ }^{\dagger}$ Equal contributors

Department of Biological Science, College of Science, Sungkyunkwan University,

Suwon 16419, South Korea
}

ten CYP clans and 19 families in vertebrates $[6,7,9]$. CYP genes in families 1 to 4 are mainly related to xenobiotic metabolism and are more diverse than the other CYPs, with less sequence conservation [10, 11]. In contrast, CYP genes in families 5 to 51 mainly have endogenous functions. Many studies of CYP genes in families 1 to 4 have focused on ecotoxicological model species, including teleosts $[1,3,12]$. Zebrafish and Japanese medaka are the teleosts most commonly used to study the mechanistic action of CYPs in response to chemical compounds. These model organisms have shown that CYPs alert the organism to the presence of carcinogenic and hormonal disruptive substances in Cicosystems [13]

ver the past two decades, CYP genes have been intensively identified and characterized in fish. More than 130 CYP genes in 19 families have been identified in all 
fish species examined to date [3, 10]. For instance, Japanese pufferfish (Fugu rubripes) have 54 CYP genes (later updated to 61 CYP genes) [8], zebrafish (Danio rerio) have 94 CYP genes (without transcript variants, the number is closer to 86) [2,12], marine medaka (Oryzias melastigma) have 65 CYP genes [14], and channel catfish (Ictalurus punctatus) have 61 CYP genes [15]. In addition, CYP genes with various functions have been studied in many other fish species $[1,3,16-19]$.

Kryptolebias marmoratus is the only vertebrate that reproduces by self-fertilization. K. marmoratus is a useful laboratory fish for studying molecular ecotoxicology because it is only $3-5 \mathrm{~cm}$ long, its life cycle is just $12-$ 16 weeks, and it is easily maintained in aquaria [20]. As an ecotoxicological model species in which the entire genome has been sequenced [21-23], it has provided a platform for assessing the impact of various chemicals on the marine environment. In a previous study, nine CYP genes co-localized on a scaffold were identified and their spatio-temporal expression patterns in response to various endocrine-disrupting chemicals (EDCs) were analyzed (e.g., benzo[ $\alpha]$ pyrene, bisphenol A, octylphenol, and nonlyphenol) [24]. In this study, we identified and annotated the full complement of 74 CYP genes in $K$. marmoratus. We also analyzed the co-localized CYP2K, CYP5A, and CYP46A subfamilies and characterized their structural features.

\section{Results}

\section{Identification of CYP genes}

Using the available $K$. marmoratus genome and transcriptome assembly data, we identified 74 CYP genes and one $C Y P$ pseudogene that together mapped onto 36 scaffolds (Fig. 1; Table 1). Each scaffold contained one to ten $C Y P$ genes. The identified $C Y P$ genes were classified into ten clans $(2,3,4,7,19,20,26,46,51$, and $\mathrm{mt})$ and 17 families $(1,2,3,4,5,7,8,11,17,19,20,21,24,26$, 27, 46, and 51) (Table 1). Among the 18 teleost-specific subfamilies, $K$. marmoratus has 11 (CYP2K, CYP2N, CYP2P, CYP2V, CYP2X, CYP2Y, CYP2Z, CYP2AD, CYP3B, CYP7C, and CYP11C). Of the 74 CYP genes, four CYP genes (CYP2Z6, CYP3A176, CYP4T17, and CYP8A2) had alternatively spliced transcripts (CYP2Z6like, CYP3A177, CYP4T18, and CYP8A2-like) (Table 1). During the $C Y P$ gene identification process, we obtained evidence of an additional $C Y P$ gene near the $C Y P 2 K 38$ gene, which turned out to be a pseudogene. This pseudogene (CYP2K38pseudo) was discovered by mapping the CYP2K38 gene onto the genome scaffolds. CYP2K38pseudo showed 98\% sequence similarity in addition to structural similarity (nine exons) to CYP2K38, which is approximately $1 \mathrm{~kb}$ away on the complementary strand. However, CYP2K38pseudo has a stop codon at the end of the 4th exon. The corresponding transcript could not be identified from the RNA-seq data (Additional file 1: Figure S1).

\section{Homology of CYP genes in other fish}

Molecular phylogenetic analysis based on the inferred amino acid sequences was used to characterize the relationship of $K$. marmoratus CYP genes with CYP genes in other intensively studied fish species such as zebrafish (D. rerio), Japanese medaka (Oryzias latipes), and fugu (F. rubripes) (Fig. 2). The phylogenetic tree indicated that the clan structure was robust among these fish species with the CYP genes in clan 2 showing the most expanded pattern in K. marmoratus (Fig. 2). Compared with the zebrafish CYP genes, the $K$. marmoratus CYP genes were arranged into similar subfamilies, with the exception that CYP39, CYP2AA, and CYP2AE were lost in $K$. marmoratus (Fig. 3). For the CYP1, CYP17, CYP19, CYP20, CYP21, and CYP46 families, the gene members and their structures in $K$. marmoratus were similar to those in zebrafish but with different degrees of sequence similarity. Each CYP2R1 and CYP2U1 subfamily has a single $C Y P$ gene consisting of five exons. These genes can be considered to be orthologs of CYP2R1 and CYP2U1 in humans and in other fish [12, 15, 25]. CYP1A, CYP1B, CYP2U, and CYP2R appear to be evolutionarily conserved across species. In $K$. marmoratus, the CYP26 family consists of CYP26A1, CYP26B1, and CYP26C1, as shown in zebrafish. In both species, $C Y P 26 A 1$ and $C Y P 26 C 1$ showed similar gene structures. While zebrafish CYP26B1 has six exons, $K$. marmoratus $C Y P 26 B 1$ has seven exons. This difference is because the 3rd exon in zebrafish is split into two exons, thus forming the 3rd and 4th exons in K. marmoratus. The CYP2 family is largest in $K$. marmoratus and consists of 32 genes in nine subfamilies. The nine genes (CYP2N22, CYP2N23, CYP2AD12, CYP2AD-iso, CYP2P16, CYP2P17, CYP2P18, CYP2P19, and CYP2P20) in the three CYP2 families are homologous to human CYP2J2 because phylogenetic analysis grouped them together into a clade with the zebrafish CYP2 subfamilies (CYP2N, CYP2P, CYP2V, CYP2AD, and CYP2AE) (Additional file 2: Figure S2). All nine genes have been reported to be located in tandem on a scaffold (NW_016094248) and to share synteny with 11 zebrafish genes [24]. Four CYP2X genes are present in two separate scaffolds. The CYP2X subfamily showed a different gene structure from other members in the CYP2 family in this species with the exceptions of CYP2R1 and CYP2U1. Gene members in $C Y P 2 X$ have 11 exons instead of 9 (Table 1), because the 5th and 7th exons are split into two exons each. CYP2X25 is located on scaffold NW_016096522, while the other three CYP2Xs (CYP2X27, CYP2X24, and CYP2X26) are located in tandem on scaffold NW_016094701 (Fig. 1). Based on their sequence identity and the phylogenetic analysis 


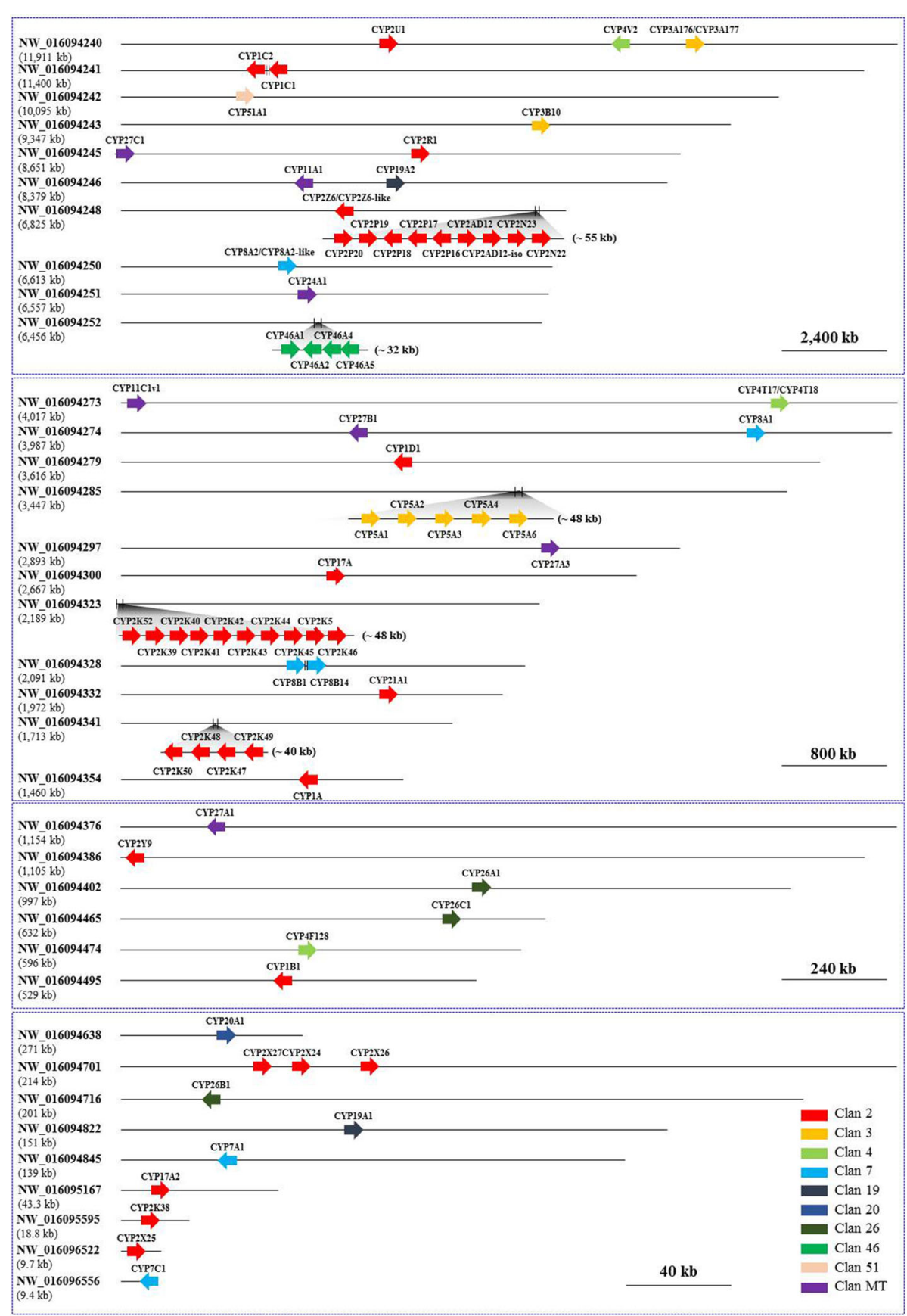

Fig. 1 Diagram of the cytochrome P450 genes and their genomic locations in K. marmoratus

results, we predicted that these four genes would be on the same scaffold. While the best mapping position of CYP2X25 was on scaffold NW_016096522, the 2nd best location was the same area of CYP2X26. This finding is likely because the two proteins share $86 \%$ amino acid sequence similarity and the genes share $90 \%$ nucleotide sequence identity. Considering that the gaps in the area spanning the CYPX26 gene on scaffolds NW_016094701 and NW_016096522 were relatively short, we suspected that an assembly error had occurred in the region. In order to confirm whether this was assembly errors or not, we mapped four $C Y P 2 X$ genes onto the published genome scaffolds of another killifish strain with the higher number of contigs [22]. Unfortunately, only two CYP2X genes (CYP2X24 and CYP2X25) were mapped onto one scaffold. However, CYP2X25, which was isolated in this study, was mapped to one scaffold with one of four genes together and the scaffold was mapped back onto the 
Table 1 CYP genes identified in K. marmoratus

\begin{tabular}{|c|c|c|c|c|c|c|c|c|c|c|c|}
\hline Clan & Family & CYP genes & $\begin{array}{l}\text { ORF length } \\
\text { (bp) }\end{array}$ & $\begin{array}{l}\text { No. of } \\
\text { Exons }\end{array}$ & Accession No. & Scaffold ID & $\begin{array}{l}\text { Scaffold } \\
\text { length (bp) }\end{array}$ & Start & End & $\begin{array}{l}\text { Gene } \\
\text { size (bp) }\end{array}$ & Strar \\
\hline \multirow[t]{41}{*}{ Clan 2} & \multirow[t]{5}{*}{ Family 1} & CYP1A & 1566 & 7 & MF326082 & NW_016094354 & $1,459,910$ & 968,181 & 965,957 & 2224 & - \\
\hline & & CYP1B1 & 1617 & 2 & MF326083 & NW_016094495 & 528,655 & 243,436 & 240,336 & 3100 & - \\
\hline & & CYP1C1 & 1578 & 1 & MF326084 & NW_016094241 & $11,400,209$ & $2,151,289$ & $2,149,703$ & 1586 & - \\
\hline & & CYP1C2 & 1575 & 1 & MF326085 & NW_016094241 & $11,400,209$ & $2,147,560$ & $2,145,986$ & 1574 & - \\
\hline & & CYP1D1 & 1587 & 7 & MF326086 & NW_016094279 & $3,616,124$ & $1,463,808$ & $1,459,468$ & 4340 & - \\
\hline & \multirow[t]{33}{*}{ Family2 } & CYP2AD12 & 1482 & 9 & MF326087 & NW_016094248 & $6,824,951$ & $6,408,131$ & $6,411,923$ & 3792 & + \\
\hline & & CYP2AD12iso & 1482 & 9 & MF326088 & NW_016094248 & $6,824,951$ & $6,413,510$ & $6,417,086$ & 3576 & + \\
\hline & & CYP2K38 & 1521 & 9 & MF326089 & NW_016095595 & 18,832 & 6285 & 9742 & 3457 & + \\
\hline & & CYP2K39 & 1506 & 9 & MF326090 & NW_016094323 & $2,188,509$ & 12,490 & 15,110 & 2620 & + \\
\hline & & CYP2K40 & 1506 & 9 & MF326091 & NW_016094323 & $2,188,509$ & 17,216 & 20,474 & 3258 & + \\
\hline & & CYP2K41 & 1506 & 9 & MF326092 & NW_016094323 & $2,188,509$ & 22,083 & 25,074 & 2991 & + \\
\hline & & CYP2K42 & 1503 & 9 & MF326093 & NW_016094323 & $2,188,509$ & 27,002 & 31,421 & 4419 & + \\
\hline & & CYP2K43 & 1506 & 9 & MF326094 & NW_016094323 & $2,188,509$ & 32,776 & 35,523 & 2747 & + \\
\hline & & CYP2K44 & 1503 & 9 & MF326095 & NW_016094323 & $2,188,509$ & 39,265 & 42,491 & 3226 & + \\
\hline & & CYP2K45 & 1503 & 9 & MF326096 & NW_016094323 & $2,188,509$ & 45,259 & 48,543 & 3284 & + \\
\hline & & CYP2K46 & 1488 & 9 & MF326097 & NW_016094323 & $2,188,509$ & 57,299 & 59,861 & 2562 & + \\
\hline & & CYP2K47 & 1527 & 9 & MF326098 & NW_016094341 & $1,713,428$ & 484,375 & 479,276 & 5099 & - \\
\hline & & CYP2K48 & 1419 & 9 & MF326099 & NW_016094341 & $1,713,428$ & 477,446 & 472,119 & 5327 & - \\
\hline & & CYP2K49 & 1515 & 9 & MF326100 & NW_016094341 & $1,713,428$ & 499,574 & 492,275 & 7299 & - \\
\hline & & CYP2K50 & 1521 & 9 & MF326101 & NW_016094341 & $1,713,428$ & 466,024 & 461,828 & 4196 & - \\
\hline & & CYP2K51 & 1500 & 9 & MF326102 & NW_016094323 & $2,188,509$ & 50,504 & 53,526 & 3022 & + \\
\hline & & CYP2K52 & 1350 & 9 & MF326103 & NW_016094323 & $2,188,509$ & 3986 & 9356 & 5371 & + \\
\hline & & CYP2N22 & 1488 & 9 & MF326104 & NW_016094248 & $6,824,951$ & $6,424,268$ & $6,427,747$ & 3479 & + \\
\hline & & CYP2N23 & 1494 & 9 & MF326105 & NW_016094248 & $6,824,951$ & $6,419,087$ & $6,422,845$ & 3758 & + \\
\hline & & CYP2P16 & 1497 & 9 & MF326106 & NW_016094248 & $6,824,951$ & $6,406,727$ & $6,401,086$ & 5641 & - \\
\hline & & CYP2P17 & 1497 & 9 & MF326107 & NW_016094248 & $6,824,951$ & $6,399,381$ & $6,393,620$ & 5761 & - \\
\hline & & CYP2P18 & 1497 & 9 & MF326108 & NW_016094248 & $6,824,951$ & $6,392,341$ & $6,385,519$ & 6822 & - \\
\hline & & CYP2P19 & 1497 & 9 & MF326109 & NW_016094248 & $6,824,951$ & $6,379,679$ & $6,384,024$ & 4345 & + \\
\hline & & CYP2P20 & 1506 & 9 & MF326110 & NW_016094248 & $6,824,951$ & $6,373,446$ & $6,378,689$ & 5243 & + \\
\hline & & CYP2R1 & 1560 & 5 & MF326111 & NW_016094245 & $8,651,236$ & $4,619,472$ & $4,622,983$ & 3511 & + \\
\hline & & CYP2U1 & 1602 & 5 & MF326112 & NW_016094240 & $11,911,191$ & $4,154,835$ & $4,159,576$ & 4741 & + \\
\hline & & CYP2X24 & 1461 & 11 & MF326113 & NW_016094701 & 214,116 & 47,337 & 53,345 & 6008 & + \\
\hline & & CYP2X25 & 1461 & 11 & MF326114 & NW_016096522 & 9746 & N/A & 5537 & N/A & + \\
\hline & & CYP2X26 & 1479 & 11 & MF326115 & NW_016094701 & 214,116 & 56,638 & 71,729 & $\approx 15,091$ & + \\
\hline & & CYP2X27 & 1458 & 11 & MF326116 & NW_016094701 & 214,116 & 35,726 & 45,002 & $\approx 9276$ & + \\
\hline & & CYP2Y9 & 1476 & 9 & MF326117 & NW_016094386 & $1,104,698$ & 13,051 & 9566 & 3485 & - \\
\hline & & CYP2Z6 & 1515 & 9 & MF326118 & NW_016094248 & $6,824,951$ & $3,433,325$ & $3,429,696$ & 3629 & - \\
\hline & & CYP2Z6-like* & 1500 & 9 & MF326119 & NW_016094248 & $6,824,951$ & $3,433,325$ & $3,429,696$ & 3629 & - \\
\hline & \multirow[t]{2}{*}{ Family17 } & CYP17A1 & 1548 & 8 & MF326142 & NW_016094300 & $2,667,381$ & $1,094,110$ & $1,104,539$ & 10,429 & + \\
\hline & & CYP17A2 & 1539 & 9 & MF326143 & NW_016095167 & 43,372 & 7511 & 12,189 & 4678 & + \\
\hline & Family21 & CYP21A1 & 1572 & 12 & MF326147 & NW_016094332 & $1,971,969$ & $1,370,794$ & $1,374,238$ & 3444 & + \\
\hline \multirow[t]{2}{*}{ Clan3 } & \multirow[t]{2}{*}{ Family3 } & CYP3A176 & 1530 & 13 & MF326120 & NW_016094240 & $11,911,191$ & $8,795,434$ & $8,800,292$ & 4858 & + \\
\hline & & CYP3A177* & 1548 & 12 & MF326121 & NW_016094240 & $11,911,191$ & $8,795,434$ & $8,799,969$ & 4535 & + \\
\hline
\end{tabular}


Table 1 CYP genes identified in K. marmoratus (Continued)

\begin{tabular}{|c|c|c|c|c|c|c|c|c|c|c|c|}
\hline Clan & Family & CYP genes & $\begin{array}{l}\text { ORF length } \\
\text { (bp) }\end{array}$ & $\begin{array}{l}\text { No. of } \\
\text { Exons }\end{array}$ & Accession No. & Scaffold ID & $\begin{array}{l}\text { Scaffold } \\
\text { length (bp) }\end{array}$ & Start & End & $\begin{array}{l}\text { Gene } \\
\text { size (bp) }\end{array}$ & Strand \\
\hline & & CYP3B10 & 1485 & 13 & MF326122 & NW_016094243 & $9,347,475$ & $2,955,181$ & $2,949,946$ & 5235 & - \\
\hline & Family5 & CYP5A1 & 1701 & 13 & MF326127 & NW_016094285 & $3,446,830$ & $2,031,496$ & $2,035,382$ & 3886 & + \\
\hline & & CYP5A2 & 1662 & 13 & MF326128 & NW_016094285 & $3,446,830$ & $2,037,833$ & $2,044,122$ & $\approx 6289$ & - \\
\hline & & CYP5A3 & 1656 & 13 & MF326129 & NW_016094285 & $3,446,830$ & $2,046,601$ & $2,051,404$ & 4803 & + \\
\hline & & CYP5A4 & 1722 & 13 & MF326130 & NW_016094285 & $3,446,830$ & $2,052,641$ & $2,057,508$ & 4867 & + \\
\hline & & CYP5A6 & 1668 & 13 & MF326131 & NW_016094285 & $3,446,830$ & $2,068,924$ & $2,077,955$ & 9031 & + \\
\hline \multirow[t]{4}{*}{ Clan4 } & Family4 & CYP4F128 & 1617 & 13 & MF326123 & NW_016094474 & 596,310 & 272,969 & 277,073 & 4104 & + \\
\hline & & CYP4T17 & 1539 & 12 & MF326124 & NW_016094273 & $4,016,886$ & $3,420,192$ & $3,425,137$ & 4945 & + \\
\hline & & CYP4T18* & 1575 & 10 & MF326125 & NW_016094273 & $4,016,886$ & $3,420,192$ & $3,425,137$ & 4945 & + \\
\hline & & CYP4V2 & 1623 & 11 & MF326126 & NW_016094240 & $11,911,191$ & $7,707,782$ & $7,701,568$ & 6214 & - \\
\hline \multirow[t]{7}{*}{ Clan7 } & Family7 & CYP7A1 & 1539 & 8 & MF326132 & NW_016094845 & 138,999 & 31,992 & 26,587 & 5405 & - \\
\hline & & CYP7C1 & 1563 & 5 & MF326133 & NW_016096556 & 9473 & 9282 & 6496 & 2786 & - \\
\hline & Family8 & CYP8A1 & 1446 & 10 & MF326134 & NW_016094274 & $3,987,237$ & $3,283,074$ & $3,288,823$ & 5749 & + \\
\hline & & CYP8A2 & 1467 & 10 & MF326135 & NW_016094250 & $6,612,770$ & $5,812,657$ & $5,818,781$ & 6124 & + \\
\hline & & CYP8A2-like* & 1521 & 10 & MF326136 & NW_016094250 & $6,612,770$ & $5,810,209$ & $5,818,781$ & 8572 & + \\
\hline & & CYP8B1 & 1530 & 1 & MF326137 & NW_016094328 & $2,090,648$ & 988,883 & 990,412 & 1529 & + \\
\hline & & CYP8B14 & 1530 & 1 & MF326138 & NW_016094328 & $2,090,648$ & 995,773 & 997,302 & 1529 & + \\
\hline \multirow[t]{2}{*}{ Clan19 } & Family 19 & CYP19A1 & 1551 & 9 & MF326144 & NW_016094822 & 150,677 & 61,672 & N/A & N/A & + \\
\hline & & CYP19A2 & 1518 & 10 & MF326145 & NW_016094246 & $8,378,829$ & $5,605,491$ & $5,608,355$ & 2864 & + \\
\hline Clan20 & Family20 & CYP20A1 & 1389 & 13 & MF326146 & NW_016094638 & 271,067 & 153,258 & 157,717 & 4459 & + \\
\hline \multirow[t]{3}{*}{ Clan26 } & Family26 & CYP26A1 & 1467 & 7 & MF326149 & NW_016094402 & 996,503 & 529,169 & 537,817 & 8648 & + \\
\hline & & CYP26B1 & 1539 & 7 & MF326150 & NW_016094716 & 201,440 & 39,690 & 10,153 & $\approx 29,537$ & - \\
\hline & & CYP26C1 & 1608 & 7 & MF326151 & NW_016094465 & 632,235 & 493,674 & 502,741 & 9067 & + \\
\hline \multirow[t]{4}{*}{ Clan46 } & Family46 & CYP46A1 & 1512 & 15 & MF326156 & NW_016094252 & $6,456,249$ & $3,898,087$ & $3,893,214$ & 4873 & - \\
\hline & & CYP46A2 & 1515 & 15 & MF326157 & NW_016094252 & $6,456,249$ & $3,614,329$ & $3,621,112$ & 6783 & + \\
\hline & & CYP46A4 & 1527 & 15 & MF326158 & NW_016094252 & $6,456,249$ & $3,606,320$ & $3,612,983$ & 6663 & + \\
\hline & & CYP46A5 & 1515 & 15 & MF326159 & NW_016094252 & $6,456,249$ & $3,589,333$ & $3,605,213$ & 15,880 & + \\
\hline Clan51 & Family51 & CYP51A1 & 1497 & 10 & MF326160 & NW_016094242 & $10,095,097$ & $8,228,424$ & $8,223,720$ & 4704 & - \\
\hline \multirow[t]{7}{*}{ Clanmt } & Family11 & CYP11A1 & 1572 & 9 & MF326140 & NW_016094246 & $8,378,829$ & $4,196,019$ & $4,193,094$ & 2925 & - \\
\hline & & CYP11C1V1 & 1632 & 9 & MF326141 & NW_016094273 & $4,016,886$ & 9463 & 16,380 & 6917 & + \\
\hline & Family24 & CYP24A1 & 1542 & 11 & MF326148 & NW_016094251 & $6,557,273$ & $3,641,436$ & $3,635,899$ & 5537 & - \\
\hline & Family27 & CYP27A1 & 1593 & 9 & MF326152 & NW_016094376 & $1,154,157$ & 145,481 & 140,290 & 5191 & - \\
\hline & & CYP27A3 & 1614 & 11 & MF326153 & NW_016094297 & $2,892,702$ & $2,218,077$ & $2,237,829$ & $\approx 19,752$ & + \\
\hline & & CYP27B1 & 1566 & 9 & MF326154 & NW_016094274 & $3,987,237$ & $1,230,560$ & $1,227,105$ & 3455 & - \\
\hline & & CYP27C1 & 1623 & 9 & MF326155 & NW_016094245 & $8,651,236$ & 41,377 & 52,309 & $\approx 10,932$ & + \\
\hline
\end{tabular}

*Alternatively spliced transcript of the gene directly above

$\mathrm{N} / \mathrm{A}$, the exact location of the gene could not be determined because the gene was mapped to the end of the scaffold

$\approx$ Approximate genome size because the scaffold contains 'Ns' in the gene area

CYP2Xs-containing scaffold (NW_016094701) of this study. Based on this analysis, this isolation of CYP2X25 is more likely due to the assembly error, instead of the translocation.

\section{Tandem duplicated CYP genes}

Similar to the CYP evolution patterns in other animals, tandem duplication of a number of CYP genes was observed in the $K$. marmoratus genome. Of $74 C Y P$ genes from $K$. marmoratus, we examined the region of tandem duplicated CYP genes to investigate the duplicated pattern in the genome. Eight scaffolds contained more than two copies of tandem duplicated CYP genes, five of which had $C Y P$ genes with more than four copies (Fig. 1). Of CYP2K subfamily, ten CYP2K genes (CYP2K39, 


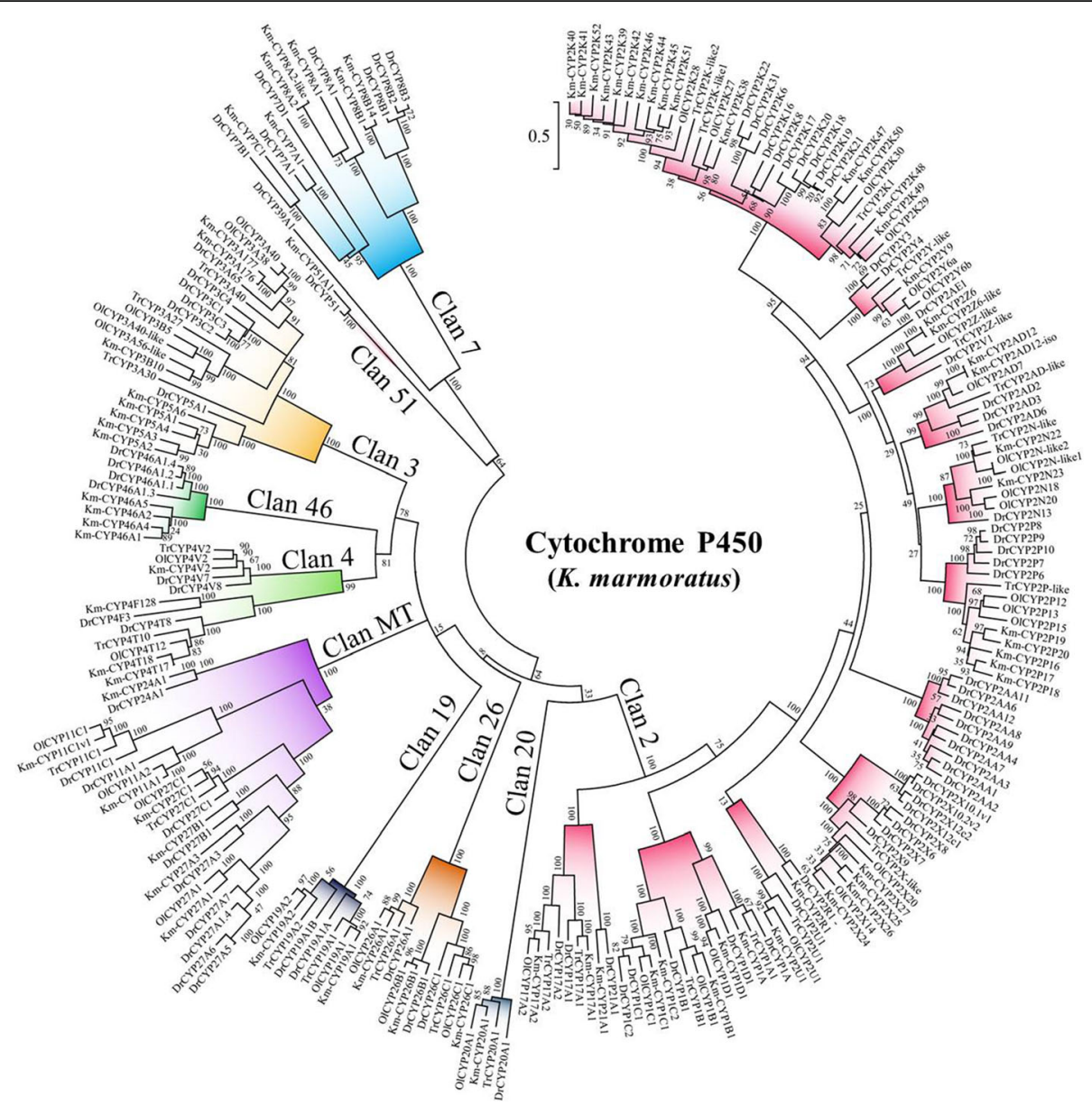

Fig. 2 Phylogenetic tree of cytochrome P450 genes in K. marmoratus and other teleosts. Km, Kryptolebias marmoratus; Ol, Oryzia latipes; Dr., Danio rerio; Tr, Takifugu rubripes

CYP2K40, CYP2K41, CYP2K42, СYР2K43, СYР2K44, CYP2K45, CYP2K46 CYP2K51, and CYP2K52) were clustered in the 48-kb region of scaffold NW_016094323 and four CYP2K genes (CYP2K47, CYP2K48, CYP2K49, and CYP2K50) were in the $40 \mathrm{~kb}$ region of scaffold NW_016094341 (Figs. 1 and 4). Synteny analysis revealed that zebrafish have eight CYP2K genes clustered in a homologous region (116 kb), whereas T. rubripes and O. latipes have only two copies of CYP2K genes in the 9-kb and 10kb regions, respectively (Fig. 4a). Four CYP2K genes comprise another cluster on scaffold NW_016094341 (Fig. 4). Phylogenetic analysis of CYP2K genes in fish (with human genes as the outgroup) showed that the four $C Y P 2 K$ genes are similar to medaka-CYP2KP29 and medaka-CYP2K30, which are located on chromosome 24 (Fig. 5). Synteny analysis of this region did not identify homologous genes outside the clusters for any species (Fig. 4). In addition, the CYP5A tandem genes and the CYP46A tandem genes were clustered in scaffolds NW_016094285 and NW_016094252, respectively (Fig. 1). While zebrafish has only one gene in the CYP5A subfamily, $K$. marmoratus has five copies of $C Y P 5 A$ genes $(5 A 1,5 A 2,5 A 3,5 A 4$, and $5 A 6)$. These copies were also arrayed in tandem on scaffold NW_016094285 (Figs. 1 and 6a). Synteny analysis showed homology with zebrafish chromosome 18 (Fig. 4b). In the CYP46A subfamily, CYP46A1, CYP46A2, CYP46A4, and CYP46A5 also showed tandem duplication on scaffold NW_016094252 in the K. marmoratus genome (Fig. 6b). This region seemed to share synteny with $D$. rerio chromosome 20, Japanese medaka chromosome 24, and Fugu chromosome 16 (Fig. 6b), although some gene order mismatches in both $K$. marmoratus and $D$. rerio were observed, compared with pufferfish and Japanese medaka. Considering the presence of a big gap ( 170 kb) between bcl-11 and CYP46A1 in K. marmoratus, we also suspected the assembly error in this region. However, comparing with the genome assembly by Kelley et al. [22], the gene order in $K$. marmoratus in both assemblies was consistent. In pufferfish and Japanese medaka, two copies of CYP46A-like tandem genes were surrounded by the genes, $c c d c 85 c b$ and $i s m 2 b$, in the synteny region. It seemed that CYP46As and neighboring genes, including $c c d c 85 c b, C C N K$, and $b c l-11$, 


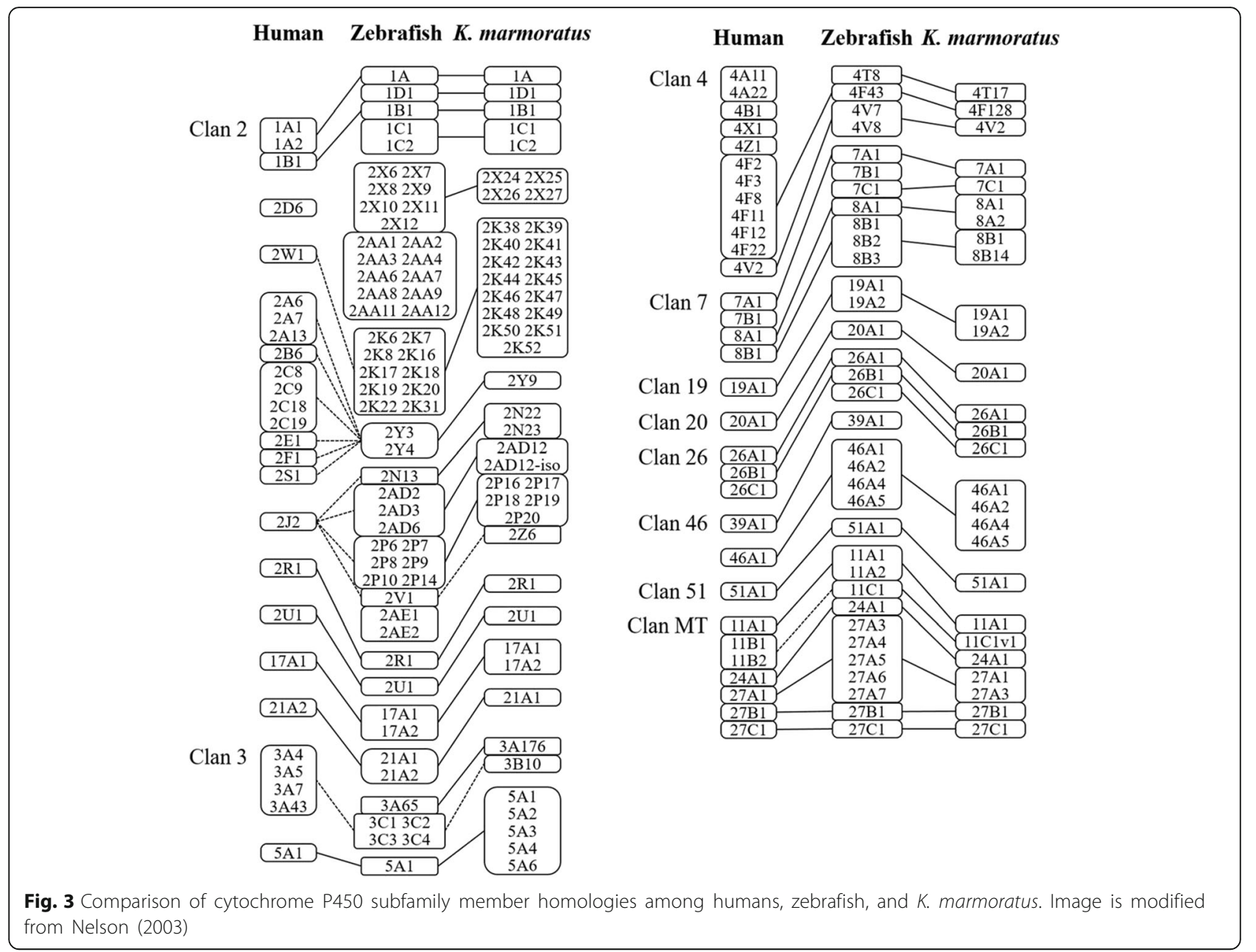

were inverted in the area with an additional duplication of CYP46A copies, which was uncertain if the tandem duplication occurred before or after the inversion. Thus, based on the synteny analysis of the zebrafish, gene duplication probably has occurred prior to the inversion, although zebrafish seems to have small difference in the evolutionary repertoires in this region.

\section{Discussion}

\section{Comparison of CYP subfamilies in teleosts}

Using whole genome sequences and RNA-seq data, we identified a full complement of $C Y P$ genes in the $K$. marmoratus genome. $K$. marmoratus has a total of 74 CYP genes in 17 families within 10 clans. Ten clans and 19 families have been reported in vertebrate animals $[6,7,9]$. Among the 19 CYP families of vertebrates, we did not identify the CYP39 or CYP16 family in $K$. marmoratus. CYP39 families have recently been identified in teleost fish. Before this discovery, the CYP39 family was thought to be unique to mammals or to have arisen in the tetrapod lineage after it diverged from fish [8]. Goldstone et al. [12] reported the presence of CYP39 genes in zebrafish. However, CYP39 genes were not found in other published fish genomes, including Fugu. K. marmoratus does not have the CYP16 family. This family was lost in mammals and is also absent from zebrafish. Out of all published fish genomes, CYP16 was reported only in Fugu [15].

\section{Gene expansion by lineage-specific duplication}

While CYP genes are commonly expanded by tandem duplication [6, 15, 26-28], the basic mechanisms by which a certain gene is selected for such duplication remain unclear. We predominantly focused on comparing the $K$. marmoratus $C Y P$ genes with the zebrafish $C Y P$ genes because the two species have similar total numbers of CYP genes and the homology of their CYP genes with all human CYP genes is known (Fig. 3). Phylogenetic and synteny analyses revealed lineage-specific duplication of many CYP genes, which was apparent in some tandem duplications of $C Y P$ genes. Among the eight genomic regions where tandemly duplicated $C Y P$ genes were located in the $K$. marmoratus genome, five subfamilies (CYP2P, CYP2AD, CYP2K, CYP5A, CYP8B, and CYP46A) in the 


\section{a}

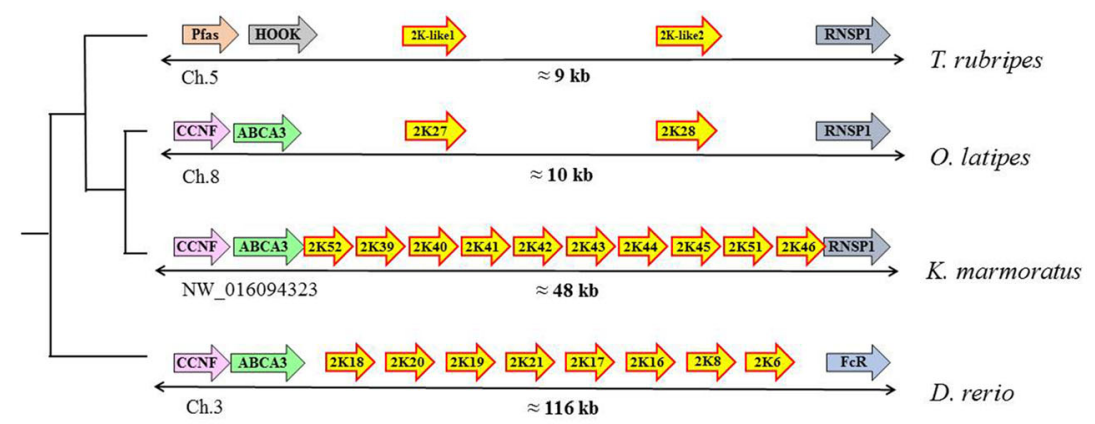

b

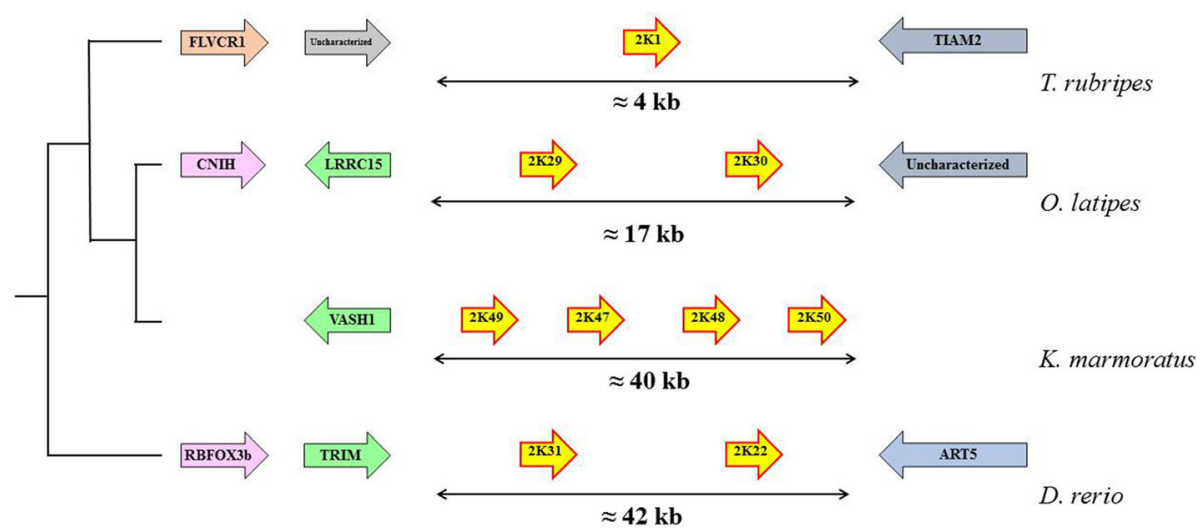

Fig. 4 Synteny analysis of CYP2K genes of $K$. marmoratus and other teleosts. a) Synteny of the CYP2K39-46, 2 K51, and 2 K52 genes. b) Synteny of the CYP2K47-50 genes

four regions showed lineage-specific duplication (Figs. 1 and 2). Although the gene members in the subfamilies were duplicated in a lineage-specific manner with different copy numbers, the syntenies (including the tandem duplicated genes) were the same between the two species (Fig. 3) [24]. Specifically, CYP46As in K. marmoratus and zebrafish showed strong homology within gene members and gene structures, albeit with different degrees of sequence similarity, compared to other subfamilies with the same syntenies. However, we note that gene order in the $K$. marmoratus CYP46As synteny is different, suggesting that both species appear to have undergone evolutionary events independently after the tandem duplication of CYP46A. CYP46A1 has been identified in many species, including teleosts, and plays an important role in cholesterol turnover in the central nervous system in vertebrates [29]. In humans, CYP46A1 functions as a cholesterol 24(S)-hydroxylase and a 24-hydroxy-cholesterol-hydroxylase [29-31]. Although mutations in CYP46A1 have been associated with neurodegenerative diseases such as Alzheimer's and Huntington's disease in humans [32-35], the function of CYP46A1 in teleosts has not been studied. Ten CYP2Ks on scaffold NW_016094323 belong to the subfamily that shows the highest level of lineage-specific tandem duplication in K. marmoratus, while four CYP2Ks on another scaffold do not seem to be duplicated in a lineage-specific manner and share synteny with those of zebrafish (Figs. 1 and 4).

\section{Kryptolebias marmoratus-specific gene expansion}

Cytochrome P450 enzymes have two main functions: metabolism of endogenous molecules and detoxification of xenobiotic compounds. Phylogenetic studies have suggested that CYP genes, which are responsible for the endogenous functions, are stable across animal species and that copy expansion is rare [11]. In contrast, CYP genes related to xenobiotic metabolism have been shown to be phylogenetically unstable with a relatively high rate of birth-death evolution [11, 36, 37]. Within this context, the most apparent gene expansion due to lineagespecific tandem duplication in $K$. marmoratus occurred in two CYP subfamilies, CYP2K and CYP5A. Similar to what has been observed in other teleost species, $C Y P 2 K$ was the most expanded subfamily in $K$. marmoratus (Fig. 4). Since $C Y P 2 K$ s are highly expanded in teleosts and the members in $C Y P 2 K$ vary across species, the 


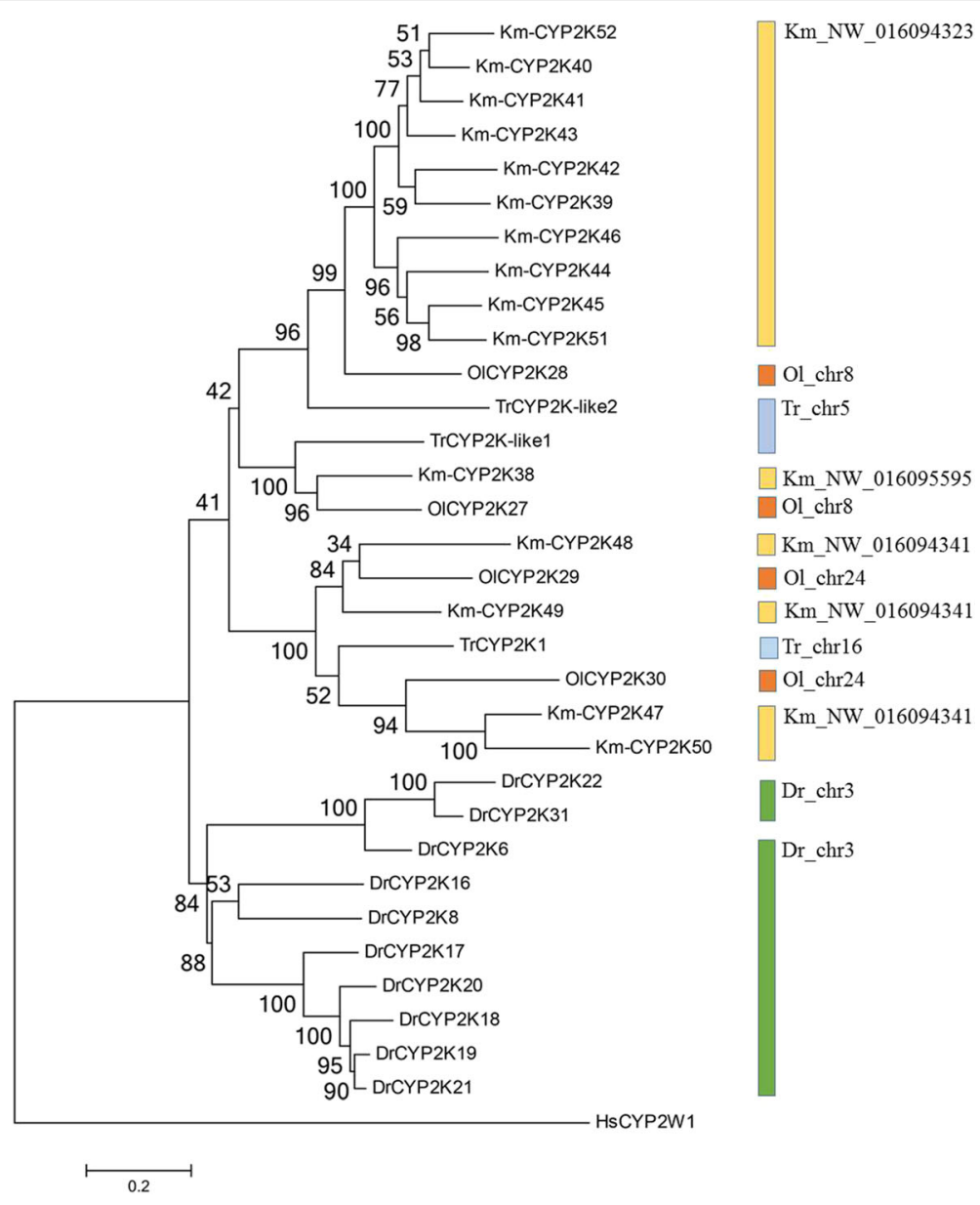

Fig. 5 Phylogenetic tree of the CYP2K subfamily in K. marmoratus and other fish species with an outgroup (CYP2W1) from human. Colored bars at right side of the tree stand for grouping gene copies on particular chromosomes or scaffolds. Km, Kryptolebias marmoratus; Ol, Oryzias latipes; Dr., Danio rerio; Tr, Takifugu rubripes; Hs, Homo sapiens

functions of $C Y P 2 K$ genes have received comparatively little attention. CYP2Ks share synteny with human CYP2W1, a tumor-specific CYP that oxidizes indole and chlorzoxazone [38-40]. Rainbow trout CYP2K1 and zebrafish CYP2K6 show an orthologous relationship and both metabolize aflatoxin $\mathrm{B}_{1}\left(\mathrm{AFB}_{1}\right)$ to exo-8,9-AFB $\mathrm{A}_{1} \mathrm{ep-}$ oxide, which is carcinogenic. However, their metabolic features differ somewhat, as only rainbow trout CYP2K1 can metabolize lauric acid [13, 41]. Based on the clan identity of CYP2K, the expansion by high level tandem duplication may have resulted from the diversity of exogenous xenobiotic substrates. Thus, rapid evolutionary selection could have favored tandem duplication as a means of coping with xenobiotic stress.

Kryptolebias marmoratus have five copies (CYP5A1, CYP5A2, CYP5A3, CYP5A4, and CYP5A6) of CYP5A subfamily members, while other teleosts including zebrafish, pufferfish, and channel catfish maintain the subfamily with a single gene copy $[8,12,15]$. CYP5A1 (thromboxane A2 synthase) catalyzes the conversion of prostaglandin $\mathrm{H} 2$ into thromboxane A2 and has been associated with human cardiovascular disease related to platelet aggregation [42]. Rather than metabolizing xenobiotics, CYP5A1 seems to be primarily involved in endogenous functions. Considering that genes involved in conserved endogenous functions are rarely expanded, the $K$. marmoratusspecific expansion of CYP5A is an interesting finding. Gene duplication and subsequent divergence of the duplicated copies are basic mechanisms by which gene subfamilies are formed and are considered essential sources of genetic complexity and evolutionary change [43-45]. Gene expansion by tandem duplication leading to gene clusters appears to be an important mechanism by which these needs are met for cytochrome $\mathrm{P} 450$ in various species. Analysis of the expression profiles of the $C Y P$ genes expanded specifically in $K$. marmoratus could generate insight into the endogenous and exogenous environmental factors driving CYP evolution. 


\section{a Synteny of CYP5A genes}

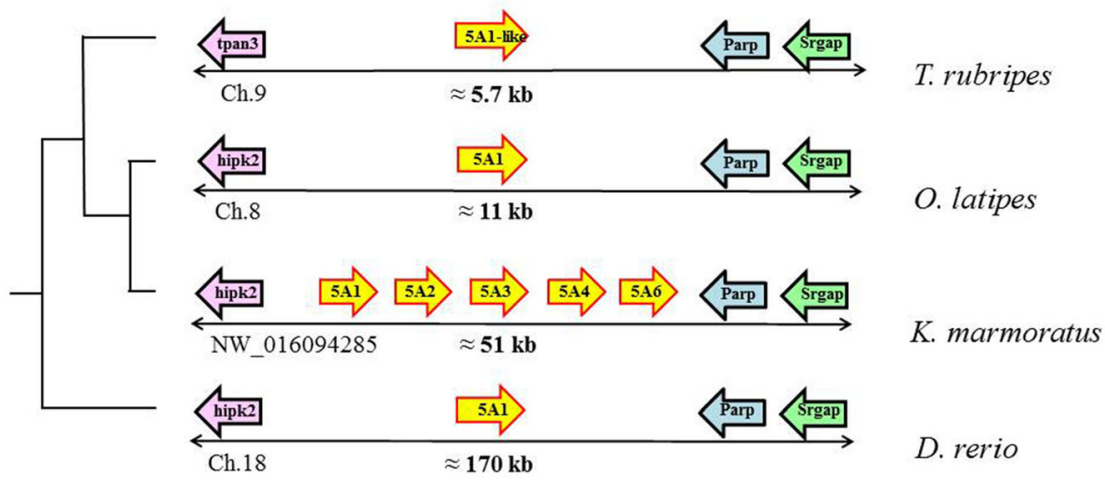

b Synteny of CYP46A genes

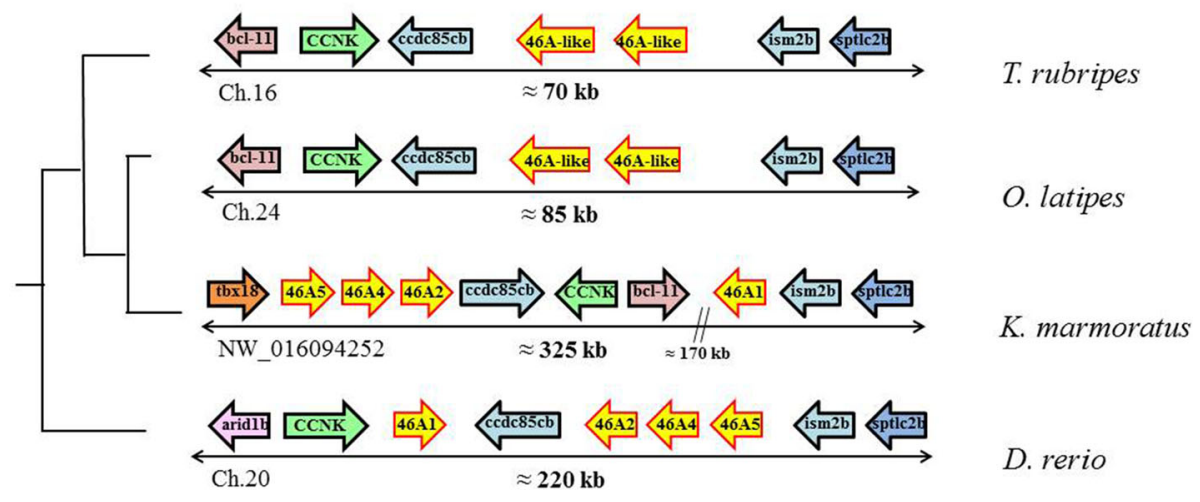

Fig. 6 Synteny analysis of tandemly duplicated CYP5A (a) and CYP46A genes (b)

\section{Methods}

\section{Fish rearing}

Kryptolebias marmoratus mangrove killifish were reared at the aquarium facility of Sungkwunkwan University (Suwon, South Korea). The fish were maintained in an automated flow-through system with constant water quality ( $\mathrm{pH} 8.0$ and 15 practical salinity units [psu]) at $25{ }^{\circ} \mathrm{C}$ under a 12/12-h light/dark cycle. The fish were maintained in glass aquaria (20 L capacity). Each aquarium accommodated 40 fish larvae (length $\approx 1.0 \pm 0.2 \mathrm{~cm}$, approximately 7 days post-hatching [dph]). Fish were fed with Artemia spp. brine shrimp $(<24 \mathrm{~h}$ after hatching) once per day.

\section{Genome-wide identification of CYP genes}

The assembled K. marmoratus whole genome (ASM164957v1) and transcriptome (SRX1765072) sequences have been published [23]. Using CYP gene sequences in other teleosts including zebrafish (D. rerio), Japanese medaka (O. latipes), and pufferfish (F. rubripes) (Additional file 3: Table S1), we searched for putative CYP sequences in the $K$. marmoratus genome. BLAST analysis of coding sequences was performed to confirm the sequence similarities. All CYP gene sequences were obtained by performing BLASTp searches of the fully assembled transcripts against the nonredundant (NR) NCBI database. A significant hit was defined as a hit with an E-value $\leq 10^{-5}$. The putative CYP coding sequences from $K$. marmoratus were translated into amino acids; further annotation was carried out by Prof. David R. Nelson (University of Tennessee Health Science Center) and Dr. Gared V. Goldstone (Woods Hole Oceanographic Institution). Gene structure was identified by comparing sequences between the genome scaffolds and transcriptomes. Synteny analysis was carried out by comparing the CYP gene clusters in $K$. marmoratus with those of Japanese medaka (O. latipes), pufferfish (T. rubripes), and zebrafish (D. rerio). Data were collected from the published chromosome assembly information at Ensemble (https://www.ensem bl.org/index.html) with further identification.

\section{Phylogenetic analysis}

The entire amino acid sequences encoded by the CYP genes of zebrafish (D. rerio) (Dr-CYPs) and Japanese medaka (O. latipes) (Ol-CYPs) were retrieved from GenBank (Additional file 3: Table S1). Multiple alignments of amino 
acid sequences from $K$. mamoratus, Japanese medaka, and zebrafish were performed with Clustal algorithm [46]. To establish a best-fit substitution model for phylogenetic analysis, the model showing the lowest score according to the Bayesian information criterion (BIC) [47] and the Akaike information criterion (AICc) $[48,49]$ was determined by maximum likelihood (ML) analysis. According to the results of the model test, the $\mathrm{LG}+\gamma+\mathrm{I}$ model was chosen to generate a phylogenetic tree using MEGA6 software (Center for Evolutionary Medicine and Informatics, Tempe, AZ, USA) [50]. For phylogenetic analysis, fulllength protein sequences were aligned and a phylogenetic tree was obtained as described above with an additional bootstrapping test (1000 replicates) [51]. Phylogeny data were deposited in the Treebase repository with the accession number 22004.

\section{Conclusions}

In this study, we identified and annotated the full complement of 74 CYP genes in K. marmoratus. We also analyzed the co-localized CYP2K, CYP5A, and CYP46A subfamilies and characterized their structural features.

\section{Additional files}

Additional file 1: Figure S1. Diagram of the process of identification of the CYP2K38pseudo gene. (DOC $4051 \mathrm{~kb}$ )

Additional file 2: Figure S2. Phylogenetic analysis of CYP genes in various fish species (marine medaka, pufferfish, stickleback, mangrove killifish) and human. (DOC $573 \mathrm{~kb}$ )

Additional file 3: Table S1. Accession numbers of genes used for synteny and phylogenetic analysis. (DOCX $19 \mathrm{~kb}$ )

\section{Abbreviations}

CYP: Cytochrome P450

\section{Acknowledgements}

We thank two anonymous reviewers for their valuable comments on the manuscript.

\section{Funding}

This work was supported by a grant to Jae-Seong Lee from the Collaborative Genome Program (PJT200620), which is funded by the Korean Ministry of Oceans and Fisheries and also supported by a grant to Bo-Young Lee from the National Research Foundation (NRF-2017R1D1A1B03036026).

\section{Availability of data and materials}

Sequencing data is available via NCBI by the accession number below. K. marmoratus whole genome sequence: ASM164957v1.

K. mamoratus transcriptome sequences: SRX1765072.

K. mamoratus CYP sequences: MF326082-MF326155.

Phylogy tree data of Figs. 2 and 5: http://purl.org/phylo/treebase/phylows/ study/TB2:S22052

\section{Authors' contributions}

BYL, DHK, HSK and BMK analyzed data and wrote the paper. JH and JSL discussed all the issues during experiment and finally confirmed the manuscript. All authors have read and approved the manuscript.

\section{Ethics approval}

All animal handling and experimental procedures were approved by the Animal Welfare Ethical Committee and the Animal Experimental Ethics Committee of the
Sungkyunkwan University (Suwon, South Korea). Experiments were carried out in accordance with the approved guidelines of the Animal Experimental Ethics Committee of the Sungkyunkwan University.

Consent for publication

Not applicable.

\section{Competing interests}

The authors declare that they have no competing interests.

\section{Publisher's Note}

Springer Nature remains neutral with regard to jurisdictional claims in published maps and institutional affiliations.

Received: 10 August 2017 Accepted: 21 December 2017

Published online: 02 January 2018

\section{References}

1. Arellano-Aguilar O, Montoya RM, Garcia CM. Endogenous functions and expression of cytochrome P450 enzymes in teleost fish: a review. Rev Fish Sci. 2009;17:541-56.

2. Saad M, Cavanaugh K, Verbueken E, Pype C, Casteleyn C, Van Ginneken C, Van Cruchten S. Xenobiotic metabolism in the zebrafish: a review of the spatiotemporal distribution, modulation and activity of cytochrome P450 families 1 to 3. J Toxicol Sci. 2016;41:1-11.

3. Uno T, Ishizuka M, Itakura T. Cytochrome P450 (CYP) in fish. Environ Toxicol Pharmacol. 2012;34:1-13.

4. Gotoh O. Evolution of cytochrome P450 genes from the viewpoint of genome informatics. Biol Pharm Bull. 2012:35:812-7.

5. Guengerich FP. Cytochrome P450 and chemical toxicology. Chem Res Toxicol. 2008;21:70-83.

6. Nelson DR, Goldstone JV, Stegman JJ. The cytochrome P450 genesis locus: the origin and evolution of animal cytochrome P450s. Philos. Trans. Roy. Soc. B Biol. Sci. 2013;368:20120474.

7. Nelson DR. Cytochrome P450 nomenclature. Methods Mol Biol. 2004;320:1-10.

8. Nelson DR. Comparison of P450s from human and Fugu: 420 million years of vertebrate P450 evolution. Arch Biochem Biophys. 2003:409:18-24.

9. Nelson DR. Progress in tracing the evolutionary paths of cytochrome P450. Biochem Biophys Acta. 2011;1814:14-8.

10. Nelson DR. The world of cytochrome P450s. Philos Trans Roy Soc B Biol Sci. 2013;368:20120430.

11. Thomas JH. Rapid birth-death evolution specific to xenobiotic cytochrome P450 genes in vertebrates. PLoS Genet. 2007;3:e67.

12. Goldstone JV, McArthur AG, Kubota A, Zanette J, Parente T, Jonsson ME, Nelson DR, Stegeman JJ. Identification and developmental expression of the full complement of cytochrome P450 genes in zebrafish. BMC Genomics. 2010;11:643

13. Wang-Buhler JL, Lee SJ, Chung WG, Stevens JF, Tseng HP, Hseu TH, Hu CH, Westerfield M, Yang YH, Miranda CL, Buhler DR. CYP2K6 from zebrafish (Danio rerio): cloning, mapping, developmental tissue expression, and aflatoxin $B_{1}$ activation by baculovirus expressed enzyme. Comp Biochem Physiol C. 2005;140:207-19.

14. Rhee J-S, Kim B-M, Choi B-S, Choi IY, Rudolf SSW, Nelson DR, Lee J-S. Whole spectrum of cytochrome P450 genes and molecular responses to wateraccommodated fractions exposure in the marine medaka. Environ Sci Technol. 2013;47:4804-12.

15. Zhang J, Yao J, Wang R, Zhang Y, Liu S, Sun L, Jiang Y, Feng J, Liu N, Nelson D, Waldbieser G, Liu Z. The cytochrome P450 genes of channel catfish: their involvement in disease defense responses as revealed by meta-analysis of RNA-Seq. Biochim Biophys Acta. 2014;1840:2813-28.

16. Buhler DR, Yang YH, Dreher TW, Miranda GL, Wang JL. Cloning and sequencing of the major rainbow trout constitutive cytochrome P450 (CYP2K1): identification of a new cytochrome P450 gene subfamily and its expression in mature rainbow trout liver and trunk kidney. Arch Biochem Biophys. 1994;312:45-51.

17. Kim J-H, Raisuddin S, Ki J-S, Lee J-S, Han K-N. Molecular cloning and $\beta$ naphthoflavone-induced expression of a cytochrome P450 1A (CYP1A) gene from an anadromous river pufferfish, Takifugu obscurus. Mar Pollut Bull. 2008:57:433-40.

18. Kim I-C, Kim YJ, Yoon Y, Kawamura S, Lee Y, Lee J-S. Cloning of cytochrome P450 1A (CYP1A) genes from the hermaphrodite fish Rivulus marmoratus and the Japanese medaka Oryzias latipes. Mar Environ Res. 2004;58:125-9. 
19. Goldstone JV, Stegeman JJ. Gene structure of the novel cytochrome P450 1D1 genes in sticleback (Gasterosteus aculeatus) and medaka (Oryzias latipes). Mar Environ Res. 2008;66:19-20.

20. Lee J-S, Raisuddin S, Schlenk D. Kryptolebias marmoratus (Poey, 1880): A potential model species for molecular carcinogenesis and ecotoxicogenomics. J Fish Biol. 2008:72:1871-89.

21. Rhee J-S, Lee J-S. Whole genome data for omics-based research on the selffertilizing fish Kryptolebia mamoratus. Mar Pollut Bull. 2014;85:532-41.

22. Kelley JL, Yee M-C, Brown AP, Richardson RR, Tatarenkov A, Lee CC, Harkins $\Pi$, Bustamiante $C D$, Earley RL. The genome of the self-fertilizing mangrove rivulus fish, Kryptolebias marmoratus: a model for studying phenotypic plasticity and adaptations to extreme environments. Genome Biol Evol. 2016:8:2145-54

23. Rhee J-S, Choi B-S, Kim J, Kim B-M, Lee Y-M, Kim I-C, Kanamori A, Choi I-Y, Schartl M, Lee J-S. Diversity and distribution of transposable elements in the genome of the only selfing hermaphroditic vertebrate Knyptolebias marmoratus. Sci Rep. 2017;7:40121.

24. Puthumana J, Kim B-M, Jeong C-B, Kim D-H, Kang H-M, Jung J-H, Kim I-C, Hwang U-K, Lee J-S. Nine co-localized cytochrome P450 genes of the CYP2N, CYP2AD, and CYP2P gene families in the mangrove killifish Kryptolebias marmoratus genome: identification and expression in response to B[a]P, BPA, OP, and NP. Aquat Toxicol. 2017;187:132-40.

25. Kirischian N, McArthur AG, Jesuthasan C, Krattenmacher B, Wilson JY Phylogenetic and Functioanl analysis of the vertebrate cytochrome P450 2 family. J Mol Evol. 2011;72:56-71.

26. Baldwin WS, Marko PB, Nelson DR. The cytochrome P450 (CYP) gene superfamily in Daphnia pulex. BMC Genomics. 2009;10:169.

27. Han J, Kim DH, Kim HS, Nelson DR, Lee JS. Genome-wide identification of 52 cytochrome P450 (CYP) genes in the copepod Tigriopus japonicus and their B[a]P-induced expression patterns. Comp Biochem Physiol D. 2017;23: 49-57.

28. Wang H, Donley KM, Keeney DS, Hoffman SM. Organization and evolution of the CYP2 gene cluster on mouse chromosome 7, and comparison with the syntenic guman cluster. Environ Health Perspect. 2003;111:1835-42.

29. Russell DW, Halford RW, Ramirez DM, Shah R, Kotti T. Cholesterol 24hydroxylase: an enzyme of cholesterol turnover in the brain. Annu Rev Biochem. 2009;78:1017-40.

30. Mast N, Norcross R, Andersson U, Shou M, Nakayama K, Bjorkhem I, Pikuleva IA. Broad substrate specificity of human cytochrome P450 46A1 which initiates cholesterol degradation in the brain. Biochemistry. 2003:42:14284-92.

31. Mast N, White MA, Bjorkhem I, Johnson EF, Stout CD, Pikuleva IA. Crystal structures of substrate-bound and substrate-free cytochrome P450 46A1, the principal cholesterol hydroxylase in the brain. Proc Natl Acad Sci U S A. 2008;105:9546-51.

32. Fourgeux C, Bron A, Acar N, Creuzot-Garcher C, Bretillon L. 24S-hydroxycholesterol and cholesterol-24S-hydroxylase (CYP46A1) in the retina: from cholesterol homeostasis to pathophysiology of glaucoma. Chem Phys Lipids. 2011;164:496-9.

33. Leoni V, Caccia C. 24s-hydroxycholesterol in plasma: a marker of cholesterol turnover in neurodegenerative diseases. Biochimie. 2013;95:595-612.

34. Fu BY, Ma SL, Tang NL, Tam CW, Lui WW, Chiu HF, Lam LC. Cholesterol 24hydroxylase (CYP46A1) polymorphisms are associated with faster cognitive deterioration in Chinese older persons: a two-year follow up study. Int J Geriatr Psychiatry. 2009;24:921-6.

35. Golanska E, Hulas-Bigoszewaka K, Sieruta M, Zawlik I, Witusik M, Gresner SM, Sobow T, Styczynska M, Peplonska B, Barcikowska M, Liberski PP, Corder EH. Earlier onset of Alzheimer's disease: risk polymorphisms within PRNP, PRND CYP46, and APOE genes. J Alzheimers Dis. 2009;17:359-68.

36. Ota T, Nei M. Divergent evolution and evolution by the birth-and-death process in the immunoglobulin VH gene family. Mol Biol Evol. 1994;11:469-82.

37. Hughes AL, Nei M. Evolution of the major histocompatibiity complex: independent origin of nonclassical class I genes in different group of mammals. Mol Biol Evol. 1989;6:559-79.

38. Edler D, Stenstedt K, Hallstrom M, Karlgren M, Ingelman-Sundberg M, Ragnhammar P. The expression of the novel CYP2W1 enzyme is an independent prognostic factor in colorectal cancer - a pilot study. Eur J Cancer. 2009:45:705-12.

39. Karlgren M, Gomez A, Stark K, Svard J, Rodriguez-Antona C, Oiw E, Bernal ML, Ramon Y, Cajal S, Johansson I, Ingelman-Sundberg M. Tumor-specific expression of the novel cytochrome P450 enzyme, CYP2W1. Biochem Biophys Res Commun. 2006:341:451-8.
40. Yoshioka H, Kasai N, Ikushiro S, Shinkyo R, Kamakura M, Ohta M, Inouye K, Sakaki T. Enzymatic properties of human CYP2W1 expressed in Escherichia coli. Biochem Biophys Res Commun. 2006;345:169-74.

41. Yang YH, Wang JL, Miranda GL, Buhler DR. CYP2M1: Cloning, sequencing, and expression of a new cytochrome P450 from rainbow trout liver with fatty acid (w6)-hydroxylation activity. Arch Biochem Biophys. 1998;352:271-80.

42. Shen RF, Tai HH. Thromboxanes: synthase and receptors. J Biomed Sci. 1998; 5:153-72.

43. Lynch M. Gene duplication and evolution. Science. 2002;297:945-7.

44. Lynch M, Conery JS. The evolutionary fate and consequences of duplicate genes. Science. 2000;290:1151-5.

45. Hurley I, Hale ME, Prince VE. Duplication events and the evolution of segmental identity. Evol Dev. 2005;7:556-67.

46. Thompson JD, Gibson TJ, Plewniak F, Jeanmougin F, Higgins DG. The CLUSTALX windows interface: flexible strategies for multiple sequence alignment aided by quality analysis tool. Nucleic Acids Res. 1997;25: 4876-82.

47. Schwarz G. Estimating the dimension of a model. Ann Stat. 1978;6:461-4.

48. Hurvich CM, Tsai C-L. Regression and time series model selection in small samples. Biometrika. 1989;76:297-307.

49. Posada D, Buckley TR. Model selection and model averaging in phylogenetics: Advatages of Akaike information criterion and Bayesian approaches over likelihood ratio tests. Syst Biol. 2004;53:793-808.

50. Tamura K, Stecher G, Peterson D, Filipski A, Kumar S. MEGA6: Molecular evolutionary genetics analysis version 6.0. Mol Biol Evol. 2013;30:2725-9.

51. Felsenstein J. Confidence limits on phylogenies: an approach using the bootstrap. Evolution. 1985;39:783-91.

\section{Submit your next manuscript to BioMed Central and we will help you at every step:}

- We accept pre-submission inquiries

- Our selector tool helps you to find the most relevant journal

- We provide round the clock customer support

- Convenient online submission

- Thorough peer review

- Inclusion in PubMed and all major indexing services

- Maximum visibility for your research

Submit your manuscript at www.biomedcentral.com/submit
) Biomed Central 